\title{
Dinámica de la transferencia de inmunoglobulina $G$ en el binomio madre-cría de llamas (Lama glama)
}

\author{
Auad, J.; Cerutti, J.; Cooper, L.G.; Aguilar, M.S.; Lozano, A. \\ Univ. Catól. Córdoba. Unidad Asociada a CONICET. Área de Cs. Agr. \\ Armada Argentina 3555, Córdoba. E-mail: jorauad@gmail.com
}

\begin{abstract}
Resumen
Auad, J.; Cerutti, J.; Cooper, L.G.; Aguilar, M.S.; Lozano, A.: Dinámica de la transferencia de inmunoglobulina $G$ en el binomio madre-cría de llamas (Lama glama). Rev. Vet. 31: 1, 78-81, 2020. En las llamas la transferencia de la inmunidad pasiva a través del calostro es un evento crítico para la supervivencia de la cría (teke). El objetivo de este trabajo fue establecer la cinética de la concentración de inmunoglobulina $\mathrm{G}$ (IgG) en tekes durante los primeros 5 meses de vida y relacionar la concentración de IgG en suero y calostro de las llamas con la concentración en suero de los tekes. Se diseñó un estudio de cohorte, observacional y analítico. Se estudiaron 25 llamas y sus respectivas crías. Se determinó la concentración de IgG en calostro y suero de las madres y en tekes según una cinética establecida desde el nacimiento hasta los 150 días de vida, empleando la técnica de inmunodifusión radial simple. Los resultados mostraron una concentración media de IgG en suero de llamas de 4311,47 $\mathrm{mg} / \mathrm{dl}$ y en calostro de $23254,9 \mathrm{mg} / \mathrm{dl}$. En los tekes -a las $0 \mathrm{~h}$ posparto- la concentración de IgG fue no dosable, alcanzando valores máximos entre las 18 y 24 h (4094,06 y 4197,95 mg/ dl respectivamente) no encontrando en este periodo diferencias con la concentración de la IgG sérica materna ( $\mathrm{p} 0,694)$. Desde las $24 \mathrm{~h}$ hasta los 120 días se observó un descenso en los niveles de $\operatorname{IgG}(\mathrm{p}<0,0001)$, registrándose un incremento a los 150 días (p 0,0001). Se concluye que los valores de IgG calostral son independientes de la concentración sérica tanto en llamas como en tekes, no existiendo asociación entre los mismos $(p<0,0001)$. El calostro aporta niveles de IgG que en los tekes logran concentraciones séricas similares a las de sus madres a las $24 \mathrm{~h}$ posparto.
\end{abstract}

Palabras clave: llama (Lama glama), crías, calostro, IgG sérica, placenta epiteliocorial.

\begin{abstract}
Auad, J.; Cerutti, J.; Cooper, L.G.; Aguilar, M.S.; Lozano, A.: Dynamics of the transfer of immunoglobulin $G$ in the binomial mother-newborn of llama (Lama glama). Rev. Vet. 31: 1, 78-81, 2020. The transfer of immunity by colostrum in llama is a critical event in the survival of the newborn (teke). The objective of this work was to establish the kinetics of the concentration of immunoglobulin $\mathrm{G}(\mathrm{IgG})$ in tekes during the first 5 months of life and to relate the concentration of IgG in serum and colostrum of the llamas with the concentration in serum of the tekes. A cohort, observational and analytical study was designed. Twenty-five llamas and their respective offspring were studied. The concentration of $\operatorname{IgG}$ in colostrum and serum of the mothers was determined, and in tekes from birth to 150 days of life, using the simple radial immunodiffusion technique. The results showed an average concentration of IgG in llama serum of $4311.47 \mathrm{mg} / \mathrm{dl}$ and in colostrum of $23254.9 \mathrm{mg} / \mathrm{dl}$. In the tekes at 0 $\mathrm{h}$, the concentration of $\operatorname{IgG}$ was not measurable, reaching maximum values between 18 and $24 \mathrm{~h},(4094.06$ and $4197.95 \mathrm{mg} / \mathrm{dl}$ respectively), not finding in this period differences with the concentration of the maternal serum IgG ( $p$ 0.694). From 24 hours to 120 days a decrease in $\operatorname{IgG}$ levels was observed $(\mathrm{p}<0.0001)$, registering an increase at 150 days ( $\mathrm{p} 0.0001)$. It is concluded that the values of colostral IgG are independent of the serum concentration in llamas and tekes, there being no association between them $(\mathrm{p}<0.0001)$. Colostrum provides levels of IgG that achieve a serum concentration in the tekes similar to those of their mothers at $24 \mathrm{hs}$ postpartum.
\end{abstract}

Key words: llama (Lama glama), newborn, colostrum, IgG, epitheliochorial placenta. 


\section{INTRODUCCIÓN}

En Argentina, la población de llamas se estima en más de 200.000 animales, siendo Jujuy la provincia con mayor número de ejemplares. En esta especie se destaca la producción de fibra y de carne, destinándose esta última al consumo regional y al autoconsumo ${ }^{9}$.

El sistema se encuentra en manos de pequeños productores, siendo una actividad de subsistencia y baja rentabilidad, debido a problemas ambientales y de manejo ${ }^{5}$. La elevada mortalidad de las crías (tekes) es uno de los principales factores que limitan su rendimiento productivo ${ }^{11}$.

Aunque los recién nacidos son inmunocompetentes, su sistema inmune no funciona de la misma manera que en el animal adulto y por lo tanto depende de la transferencia pasiva de anticuerpos ${ }^{16}$.

La placenta, epiteliocorial, impide la transferencia de inmunoglobulina $\mathrm{G}$ ( $\mathrm{IgG}$ ) de la madre al feto, por lo tanto, la protección inmunológica del teke durante las primeras semanas depende de la ingestión adecuada de calostro, así como de la eficiente permeabilidad intestinal durante las primeras horas de vida ${ }^{6}$.

En las llamas, como en los demás rumiantes, el calostro es rico en IgG, IgA e IgM, siendo IgG la principal clase de inmunoglobulina ${ }^{10}$. Esta especie tiene la particularidad de poseer dos tipos de IgG que varían en su estructura, en la que una de ellas está constituída por dímeros de cadenas pesadas (H), sin cadenas ligeras (L) ${ }^{13}$.

Las inmunoglobulinas son absorbidas por el neonato en el intestino delgado a través de células especializadas que presentan una vida media efímera, de 24 a 36 h (Rev.Cs.Vet.Fave 9: 2, 69-75). Las Ig se unen a receptores $\mathrm{Fc}$ en las células epiteliales del intestino $(\mathrm{FcRn}){ }^{17}$, las cuales captan a estas macromoléculas en forma activa por medio de pinocitosis (Am.J.Reprod. Imm. 80: 3, 1-7), y atraviesan llegando a los quilíferos y a los capilares intestinales, para alcanzar la circulación sistémica de los neonatos, obteniendo así una transfusión masiva de inmunoglobulinas maternas ${ }^{14,16}$.

Los recién nacidos que no adquieren inmunidad pasiva adecuada tienen un mayor riesgo de desarrollar enfermedades tales como diarrea, enteritis, septicemia, artritis, onfalitis y neumonía, las cuales a menudo llevan a la muerte del animal. La transferencia pasiva exitosa se logra cuando los recién nacidos tienen niveles séricos de $\operatorname{IgG}$ superiores a $1000 \mathrm{mg} / \mathrm{dl}$ a las $48 \mathrm{~h}$ de nacido $7,8,15,18,19,20$.

El objetivo de este trabajo fue establecer la cinética de la concentración de IgG en tekes durante los primeros 5 meses de vida y relacionar la concentración de dicha inmunoglobulina en suero y calostro de las llamas con el nivel en suero de los tekes.

\section{MATERIAL Y MÉTODOS}

Diseño del estudio: de cohorte, observacional y analítico. En el campus experimental de la Facultad de Ciencias Agropecuarias de la Universidad Católica de Córdoba (Argentina), se estudió una población de llamas y sus respectivas crías. Estos animales se encontraban semiestabulados y con suplementación alimentaria.

Muestras de material biológico: se tomaron $5 \mathrm{ml}$ de sangre por punción de la vena yugular a llamas en el periparto y una muestra de $20 \mathrm{ml}$ de calostro posparto de ambos medios de la glándula mamaria previo a la succión del teke. Por otra parte, se extrajo sangre por punción de la vena yugular a los tekes de acuerdo a la siguiente cinética: $0,6,12,18$ y 24 horas de nacido y 21 , $60,90,120$ y 150 días posparto. Las muestras de suero y calostro fueron almacenadas y congeladas a $-80^{\circ} \mathrm{C}$ hasta su procesamiento.

Determinaciones de laboratorio: las muestras fueron analizadas mediante el kit de inmunodifusión radial simple (IDRS) para IgG de camélidos (Triple $J$ Farms, USA)®. La lectura de los halos se realizó mediante la toma de imágenes y la medición de los diámetros correspondientes a través del dispositivo periférico WebCam Philips $S P C-530 \mathrm{Nc} \mathbb{}$, 1,3 Mp zoom óptico $x 3$, empleando el software Philips CamSuite Capture ${ }^{\circledR}$ V.2.0.15.0. Las imágenes se procesaron mediante el software Carl Zeiss AxioVision ${ }^{\circledR}$ Rel. 4.6.

Análisis estadístico: para realizar comparaciones de medias se utilizó prueba " $t$ " de Student apareada y para comparar la variabilidad se empleó la prueba de Bartlett. En todos los casos el nivel de significación fue de 0,05 y se utilizó el software R-Medic ${ }^{12}$.

\section{RESULTADOS}

Se incluyeron 25 llamas y sus respectivas crías. En Tabla 1 se detallan los valores obtenidos en suero y calostro de llamas y tekes según la cinética establecida.

Tabla 1. Concentraciones de IgG en suero y calostro de llamas y suero de tekes a diferentes intervalos de tiempo.

\begin{tabular}{lcccc}
\hline & $\begin{array}{c}\text { media } \\
(\mathrm{mg} / \mathrm{dl})\end{array}$ & $\begin{array}{c}\text { desvío } \\
\text { estándar }\end{array}$ & $\begin{array}{c}\text { mínimo } \\
(\mathrm{mg} / \mathrm{dl})\end{array}$ & $\begin{array}{c}\text { máximo } \\
(\mathrm{mg} / \mathrm{dl})\end{array}$ \\
\hline $\begin{array}{l}\text { llamas } \\
\text { suero }\end{array}$ & 4311,47 & 1017,1 & 2215,75 & 6585,7 \\
$\quad$ calostro & 23254,9 & 7067,6 & 13512,89 & 41487 \\
tekes & & & & \\
$0 \mathrm{~h}$ & 0 & 0 & 0 & 0 \\
$6 \mathrm{~h}$ & 2039,39 & 1598,82 & 0 & 4906,1 \\
$12 \mathrm{~h}$ & 3473,77 & 1614,83 & 574,16 & 5861,6 \\
$18 \mathrm{~h}$ & 4094,06 & 1371,66 & 1116,96 & 6137,8 \\
$24 \mathrm{~h}$ & 4197,95 & 1313,3 & 1591,31 & 6434,8 \\
21 días & 2156,11 & 721,47 & 764,75 & 3231,8 \\
60 días & 1664,38 & 559,52 & 833,56 & 3796,6 \\
90 días & 1762,14 & 401,25 & 975,89 & 2312,5 \\
120 días & 1880,77 & 426,87 & 1081,37 & 2589,9 \\
150 días & 2278,11 & 558,81 & 1591,31 & 3457,7 \\
\hline
\end{tabular}


A las cero horas posparto la concentración de $\operatorname{IgG}$ en los tekes fue no dosable, para comenzar a aumentar a medida que se produjo la absorción del calostro. Entre las 6 y $12 \mathrm{~h}$ presentaron una concentración menor a la de sus madres $(\mathrm{p}<0,02)$, alcanzando valores máximos y equivalentes a éstas entre las 18 y $24 \mathrm{~h}(\mathrm{p} 0,694)$.

Entre el primer día de vida y el día 120 , los niveles de IgG fueron decrecientes $(\mathrm{p}<0,0001)$, comenzando a aumentar (Figura 1) a partir de este momento (p 0,0001). Se encontraron diferencias entre la concentración de IgG en calostro con respecto a la concentración de esta inmunoglobulina en el suero de las llamas $(p<0.0001)$, hallazgo también observado entre el calostro y suero de tekes a las $24 \mathrm{~h}$ posparto $(\mathrm{p}<0,0001)$.

La variabilidad en los niveles de IgG en el suero de llamas y tekes a las $24 \mathrm{~h}$ no mostró diferencias (p 0,22$)$, e inclusive ésta disminuyó entre los 21 y 150 días de vida (p 0,09). Por su parte, la secreción calostral (Figura 2) mostró una variabilidad significativamente mayor $(\mathrm{p}<0,001)$.

\section{DISCUSIÓN}

Los niveles de inmunoglobulina $\mathrm{G}$ en el suero de las llamas hallados en este estudio fueron mayores a los reportados por otros investigadores, posiblemente debido a las diferencias en las condiciones medio-ambientales en las que se encontraban los animales de sus ensayos (pastizales naturales del altiplano peruano, sin suplementación alimentaria) ${ }^{2,6}$.
Con respecto a los niveles de $\operatorname{IgG}$ en calostro, fueron 5 veces mayores a los del suero de las llamas, lo cual se explica por el transporte activo de inmunoglobulinas del torrente sanguíneo hacia la glándula mamaria ${ }^{17}$. Esto coincide con algunos reportes (Rev.Vet. 25: 2, 105-108), mientras que otros investigadores hallaron concentraciones de IgG menores, probablemente porque este dosaje fue realizado en dromedarios ${ }^{1}$.

Al igual que en otros trabajos, la concentración máxima de IgG en suero de tekes se observó a las $24 \mathrm{~h}$ posparto ${ }^{3}$, momento en el cual el intestino deja de ser permeable a la absorción de estas macromoléculas ${ }^{16}$. En otras investigaciones de obtuvieron valores máximos después de las $24 \mathrm{~h}$ posparto ${ }^{6,20}$, aunque menores a nuestros resultados, debido a las diferencias en la cinética establecida por tales autores.

Las concentraciones de $\operatorname{IgG}$ sérica de los tekes comenzaron a descender desde las 24 horas hasta los 120 días, lo que puede ser explicado por el catabolismo normal de las inmunoglobulinas maternas y es definido como la hipogammaglobulinemia fisiológica de los recién nacidos; coincidentemente con lo reportado en otras investigaciones ${ }^{1,20}$. A pesar de que los niveles de $\operatorname{IgG}$ decayeron en este lapso, todos los valores hallados fueron mayores a $1000 \mathrm{mg} / \mathrm{dl}$, lo cual pone en evidencia que existió una exitosa transferencia pasiva de anticuerpos maternos $7,8,20$.

La observación realizada nos permite establecer que la concentración de IgG en el calostro es indepen-

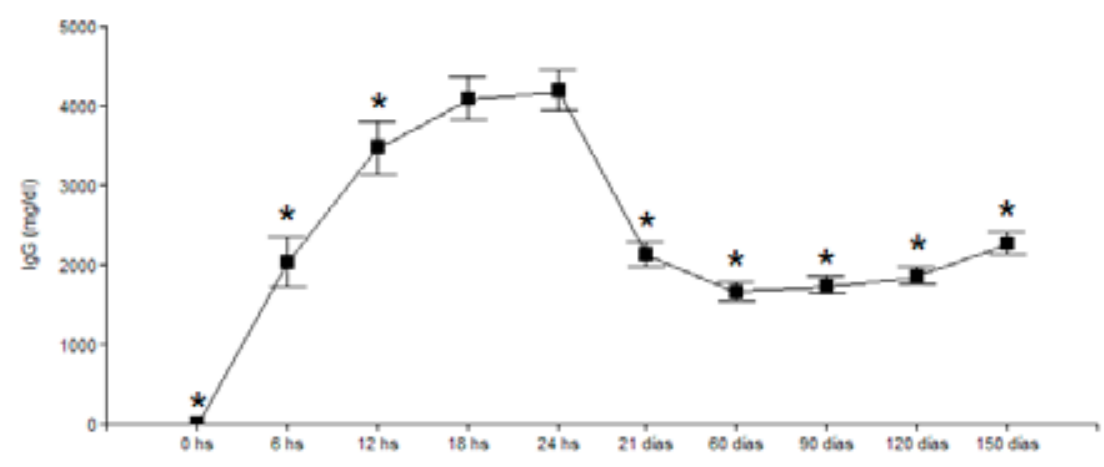

Figura 1. Evolución media de la concentración de $\operatorname{IgG}$ en suero de tekes desde las $0 \mathrm{~h}$ hasta los 150 días posparto. $\left(^{*}\right)$ corresponde a diferencias con suero de llamas $(\mathrm{p}<0,05)$.

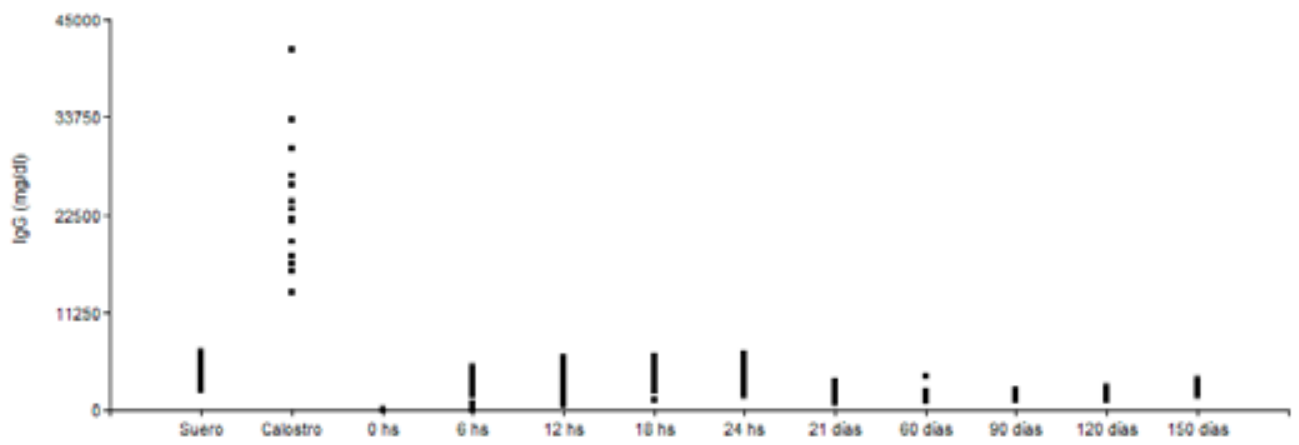

Figura 2. Concentración de IgG en suero de llamas, así como calostro y suero de tekes en los distintos intervalos de tiempo. 
diente de la IgG sérica materna y de la concentración de esta inmunoglobulina en tekes.

Por otro lado, se observó una importante variabilidad en la concentración de IgG calostral, hallazgo que coincide con otros autores ${ }^{2,6}$. Esta observación es diferente a lo descripto en otras especies (Rev.Vet. 25: 2, 105-108) y se le podría atribuir a las particularidades anatomo-fisiológicas de la glándula mamaría de los camélidos ${ }^{3,4}$.

Probablemente la elevada concentración de IgG calostral pueda vincularse a la garantización de la transferencia de la inmunidad materno-fetal, indispensable para la sobrevida de las crías en los primeros meses de vida. Estudios futuros son necesarios para explicar estas observaciones.

\section{REFERENCIAS}

1. Al-Busadah KA. 2007. Efficacy of feeding bovine and caprine colostrum to neonatal camel. J Anim Physiol Anim Nutr 6: 5-7.

2. Bravo PW, Garnica J, Fowler ME. 1997. Immunoglobulin G concentrations in periparturient llamas, alpacas and their crias. Small Rumin Res 26: 145-149.

3. Caggiano N et al. 2014.Caracterizacion de IgM, IgG total, IgG1 y anticuerpos de cadena pesada en calostro de llamas (Lama glama) mediante Elisa. Rev Complut Ciencias Vet 8: 29-40.

4. Chávez AR, Sato AS, Navarrete MZ, Cisneros JS. 2010. Anatomía macroscópica de la glándula mamaria de la llama (Lama glama). Rev Inv Vet Perú 21: 1-10.

5. FAO. 2005. Situación actual de los camélidos sudamericanos en Argentina 46: 1-62. Disponible en: file://C:/Users/ HP/Downloads/41413-56786-2-PB.pdf\%0A/http://inf oalpacas.com.pe/wp-content/uploads/2016/08/Perfil-de-fibra. pdf

6. Flodr H, Wheeler JC, Kruger DP, Olazábal J, Rosadio R. 2012. Pruebas de campo para evaluar calidad calostral en la alpaca. Rev Investig Vet Perú 23: 307-316.

7. Garmendia AE, McGuire TC. 1987. Mechanism and isotypes involved in passive immunoglobulin transfer to the newborn alpaca (Lama pacos). Am J Vet Res 48: 1465-1471.

8. Garmendia AE, Palmer G, Martini JC, McGuire TC. 1987. Failure of passive immunoglobulin transfer: a major determinant of mortality in newborn alpacas (Lama pacos). Am J Vet Res 48: 1472-1476.

9. Lamelas K, Pondé M, Sánchez PM. 2010. Anuario 2010 Subsecretaría de ganadería. Sector camélidos. http://www. produccion-animal.com.ar/produccion_de_came-lidos/ camelidos_general/07-CAMELIDOS_miniagri.pdf

10. Lima A. 2008. Estudo da flutuação sérica de anticorpos maternos nos periodos pré e pós parto e transferência de imunidade passive em cabritos recém nascidos utilizando colostro bovino e caprino. Univ. Sao Paulo. Disertación de Maestría. http://www.teses.usp.br/teses/disponiveis/11/11139/tde-15072008-124634/es.php

11. Martín C, Pinto C, Cid M. 2014. Camélidos sudamericanos: estado sanitario de sus crías. Rev Complut Ciencias Vet 4: 37-50.

12. Mangeaud A, Panigo D. 2018. R-Medic. Un programa de análisis estadísticos sencillo e intuitivo. Methodo 3: 18-22.

13. Medina MA, Fernández F, Saad S, Rebuffi G, Yapur J. 2004. Inmunoglobulinas $\mathrm{G}$ de cadenas pesadas en la leche de los camélidos sudamericanos. J Neotrop Mammal 11: 19-26.

14. Mórtola E, Pennimpede E, Gómez C, Stanchi N. 2004. Transferencia pasiva de la inmunidad pasiva en los animales domésticos. En: Introducción a la inmunobiología, Editorial UN La Plata, Argentina, 653 p.

15. Pinn TL, Gagliardo LF, Purdy SR, Appleton JA, Stokol T. 2013. Comparison of three immunoglobulin G assays for the diagnosis of failure of passive transfer of immunity in neonatal alpacas. $J$ Vet Diagn Investig 25: 91-98.

16. Tizard IR. 2009. Inmunidad en el feto y en el recién nacido. En: Introducción a la Inmunología Veterinaria. 8va ed. Barcelona, p. 223-238.

17. Ratht T et al. 2013. The immunologic functions of the neonatal Fc receptor for IgG. J Clin Immunol 33: 9-17.

18. Weaver DM et al. 2000. Passive transfer of colostral immunoglobulin $\mathrm{G}$ in neonatal llamas and alpacas. Am J Vet Res 61: 738-741.

19. Weaver DM et al. 2000. Evaluation of assays for determination of passive transfer status in neonatal llamas and alpacas. Am J Vet Res 216: 559-563.

20. Wernery U. 2001. Camelid immunoglobulins and their importance for the new-born. A review. $J$ Vet Med B 48: 561-568. 